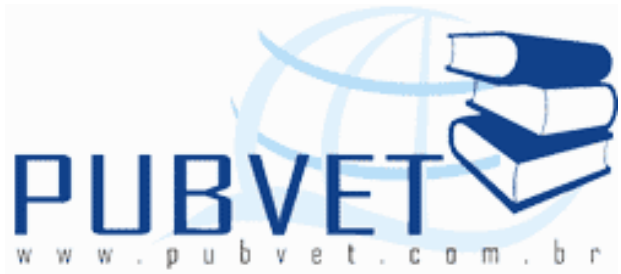

PUBVET, Publicações em Medicina Veterinária e Zootecnia.

\title{
Abordagem cirúrgica das porções média e distal do fêmur e articulação femuro-tibio-patelar de Coendou prehensilis (LINNAEUS, 1758) (Rodentia, Erethizontidae)
}

André Luiz Quagliatto Santos ${ }^{1}$, Saulo Fernandes Mano de Carvalho ${ }^{1}$, Juliana Macedo Magnino Silva², Lorena Tannús Menezes², Árthur Paulino Sanzo Kaminishi ${ }^{2}$, Liliane Rangel Nascimento ${ }^{2}$, Simone Borges Salgueiro De Simone ${ }^{2}$

Laboratório de Ensino e Pesquisa em Animais Silvestres - LAPAS, FAMEV/UFU, e-mail: quagliatto@famev.ufu.br 1. Docentes. 2. Mestrandos.

\section{Resumo}

Objetivou-se estudar a técnica de abordagem cirúrgica das porções média e distal do osso fêmur e articulação femuro-tibio-patelar de Coendou prehensilis utilizando seis exemplares adultos que foram encaminhados ao Laboratório de Ensino e Pesquisa em Animais Silvestres. Procurou-se uma abordagem cirúrgica simples e com menor número de incisões na musculatura. Para acessar a porção distal, iniciou-se o procedimento pela palpação da patela e aresta troclear lateral. O músculo vasto lateral, parte cranial do bíceps femoral e a fáscia de inserção do músculo bíceps femoral foram divulcionados. A abordagem cirúrgica da porção média do osso fêmur foi realizada através da incisão cutânea feita ao longo da margem craniolateral da diáfise do osso fêmur, desde o nível do trocânter maior até o nível da patela. As margens cutâneas foram divulsionadas e afastadas. Divulssionou-se entre o músculo 
vasto lateral e parte cranial do músculo bíceps femoral, revelando a diáfise femural. Foi constatado que é possível acessar as porções média e distal do fêmur e articulação femuro-tibio-patelar de Coendou prehensilis através de uma técnica de abordagem simples e pouco traumática.

Palavras-chave: Anatomia, ouriço cacheiro, ossos, articulação.

\title{
Cirurgical approach to the femur medium and distal portions and stifle joint of the Coendou prehensilis (LINNAEUS, 1758) \\ (Rodentia, Erethizontidae)
}

\begin{abstract}
The purpose of this study was to determine surgical techniques to the femur medium and distal portions and stifle joint using six adult specimens of Coendou prehensilis, with a simple approach and a few muscle incisions. First, patella and lateral trochlear ridge were palpated. Vastus lateralis muscle, cranial division of biceps femoris muscles and fascia of biceps femoris muscle were dissected and divulsed. The femur medium portion had a cutaneous insicion along the cranioaleral border of femural diaphysis. Cutaneous border were divulsed and removed. Dissection was made among the vastus lateralis muscle and the cranial portion of the biceps femoris muscle, exposing femoral diaphysis. It was noted that the femur medium and distal portions and stifle joint of the Coendou prehensilis can be accessed by a simple and less traumatic procedure.
\end{abstract}

Keywords: Anatomy, porcupine, bones, articulation.

\section{INTRODUÇÃO}

O Coendou prehensilis, conhecido como ouriço cacheiro, pertence à classe Mammalia, ordem Rodentia e família Erethizontidae. Está adaptado a viver em árvores e utiliza a cauda para prender-se aos galhos e mover-se 
entre eles. Durante a noite saem em busca de alimentos como folhas e cascas de árvores (CEMIG, 2004).

Assim como cães e gatos, animais silvestres são encaminhados com freqüência a clínicas veterinárias apresentando fraturas. Estas variam de acordo com a localização, mecanismo de trauma e lesões associadas em tecidos moles (VIALLE et al., 2004).

Um levantamento feito por Moreira et al (2005), relatou que 16 ouriços cacheiro foram atropelados na rodovia GO 060, trecho Goiania - Iporá no período de maio de 2004 a novembro de 2005. Animais atropelados apresentando fraturas são atendidos com freqüência no Ambulatório de Animais Silvestres do Hospital Veterinária da Universidade Federal de Uberlândia.

Bilgili e Aslanbey, (2000) atenderam 34 gatos e 18 cães apresentando fraturas, sendo que as fraturas de fêmur e úmero foram as mais comuns $(40,3 \%)$. Cirurgias ortopédicas utilizando pinos, placas ou parafusos são indicadas em casos de fraturas de ossos longos, como o fêmur.

Segundo Roush, (1995) a reparação de fraturas requer redução anatômica, rígida estabilidade e recuperação precoce da função do membro. Uma rígida estabilização elimina a mobilidade na linha de fratura assegurando conforto para o animal ao utilizar o membro, resultando em manutenção do tono e da massa muscular, mobilidade e nutrição articular. Assegura ainda, apoio do membro e manutenção da densidade óssea.

Os pinos intramedulares são mais apropriados para animais de pequeno e médio porte. São indicados também pinos cruzados ou pinos intramedulares duplos introduzidos a partir dos côndilos, podendo ser utilizados pinos de Rush ou Steinmann (GILMORE, 1990).

O conhecimento da anatomia de cada espécie animal fornece subsídios para realização de procedimentos cirúrgicos com segurança. Objetivou-se estudar a técnica de abordagem cirúrgica à porção distal do osso fêmur e articulação femuro-tibio-patelar de Coendou prehensilis. 


\section{MATERIAL E MÉTODO}

Para a realização deste trabalho foram utilizados seis exemplares adultos de Coendou prehensilis, procedentes do Zoológico Parque do Sabiá do município de Uberlândia, após mortes naturais. Os animais foram encaminhados ao Laboratório de Ensino e Pesquisa em Animais Silvestres (LAPAS), da Universidade Federal de Uberlândia, onde as a artéria aorta torácica foi canalizada e preenchida com solução corada de Neoprene Látex "450" §. A veia jugular também foi canalizada e preenchida com solução de formol a $10 \%$. A seguir, o material foi fixado em solução de formol a $10 \%$ e injetado por via intramuscular profunda, subcutânea e intravicatária, permanecendo submersos nesta solução por um período mínimo de 48 horas. Os membros pélvicos foram dissecados de modo a identificar a musculatura do membro pelvino, procurando abordar cirurgicamente as porções média e distal do osso fêmur e articulação femuro-tibio-patelar destas peças.

\section{RESULTADOS E DISCUSSÃO}

Procurou-se fazer uma abordagem cirúrgica simples e com menor número de incisões na musculatura. A abordagem cirúrgica da porção distal do osso fêmur e articulação femuro-tibio-patelar de Coendou prehensilis foi realizada através da palpação da patela e aresta troclear lateral, fazendo-se uma incisão cutânea parapatelar encurvada e estendendo-se desde o quarto distal do fêmur, por sobre a aresta troclear, até a tuberosidade da tibia. Foi feita divulsão entre o músculo vasto lateral e a parte cranial do bíceps femoral separando-os. O músculo bíceps femoral teve sua fáscia de inserção divulsionada.

A cápsula articular foi incidida cruzando a aresta troclear, curvando-se e seguindo paralelamente a borda lateral da patela e ligamento patelar. Nesta espécie pode-se observar que a articulação do joelho é fortemente aderida ao 
músculo oblíquo abdominal externo por forte tecido conjuntivo. Este reforço da articulação provavelmente deve-se ao hábito arborícola desta espécie, facilitando a subida e descida nas árvores.

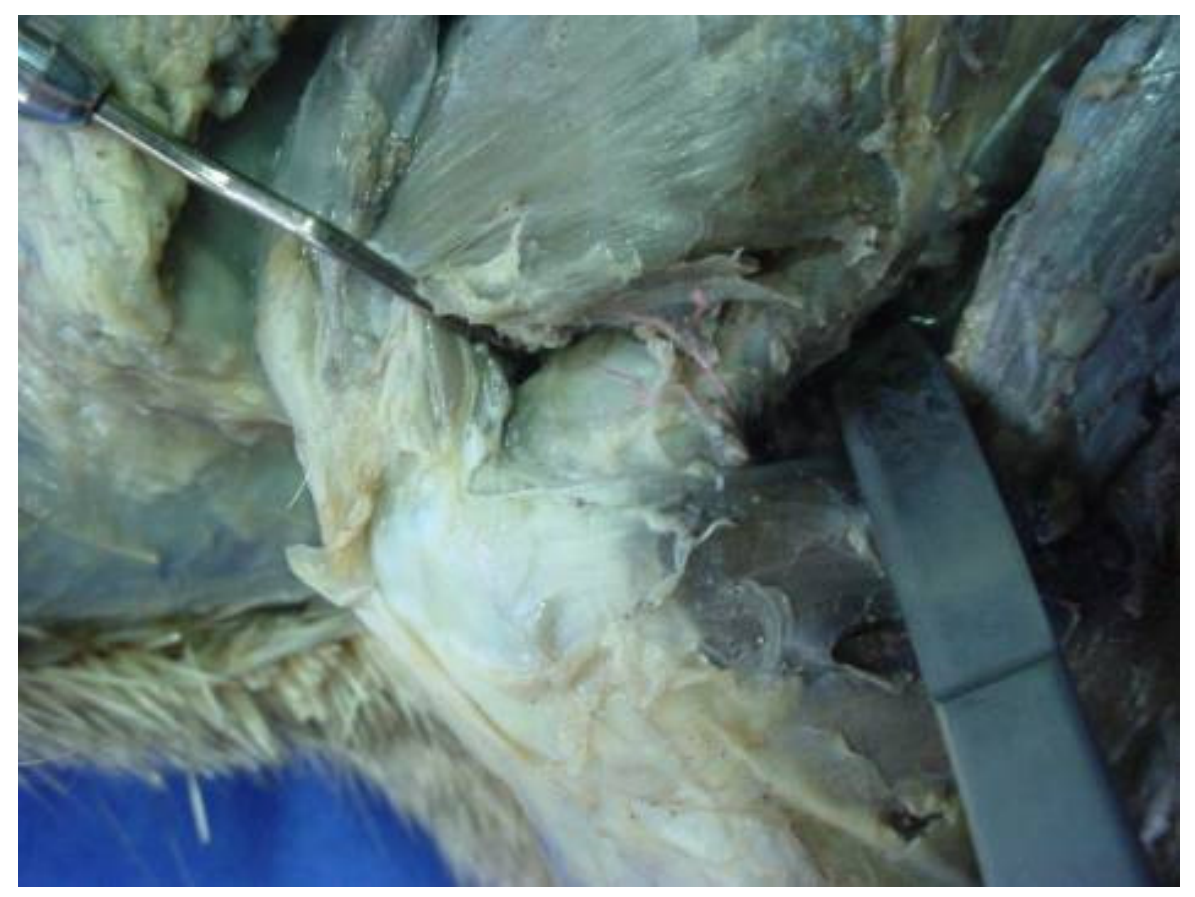

Figura 1: Fotografia da abordagem cirúrgica da porção distal do osso fêmur e articulação femuro-tibio-patelar, evidenciando o afastamento do músculo bíceps para expor o osso fêmur.

Já a abordagem cirúrgica da porção média do osso fêmur de Coendou prehensilis foi realizada através da incisão cutânea feita ao longo da margem craniolateral da diáfise do osso fêmur, desde o nível do trocânter maior até o nível da patela. As margens cutâneas foram divulsionadas e afastadas. Divulsionou-se entre os músculos vasto lateral e parte cranial do músculo bíceps femoral, revelando a diáfise femural.

Notou-se a inserção do músculo glúteo superficial na rugosidade laterocaudal no terço médio do fêmur. Foi possível observar os ramos musculares da artéria e veia femural no terço médio do fêmur.

Iamaguti et al. (1998), ao tratarem ruptura de ligamento cruzado em cães, reconstruiram o ligamento com retalho da fáscia lata. 
A abordagem cirúrgica foi realizada modificando a técnica de Paatsama, (1952).

As técnica de abordagem cirúrgica descritas por Paatsama, (1952), Raiser et al. (1998) e Iamaguti et al. (1998), foram semelhantes à técnica utilizada na em Coendou prehensilis. O que diferencia é o fato desta espécie não possuir fáscia lata e seus músculos pélvicos apresentarem inserção distal em relação as espécies domésticas. O músculo sartório apresentou-se somente na face medial da coxa, o músculo tensor da fáscia lata é potente e é o mais cranial na face lateral da coxa. Seguindo no sentido cranio-caudal da coxa a partir do tensor da fáscia lata observa-se: músculos reto femoral, músculo vasto lateral, parte cranial do músculo bíceps femoral, parte caudal do músculo bíceps femoral e músculo semi tendíneo.

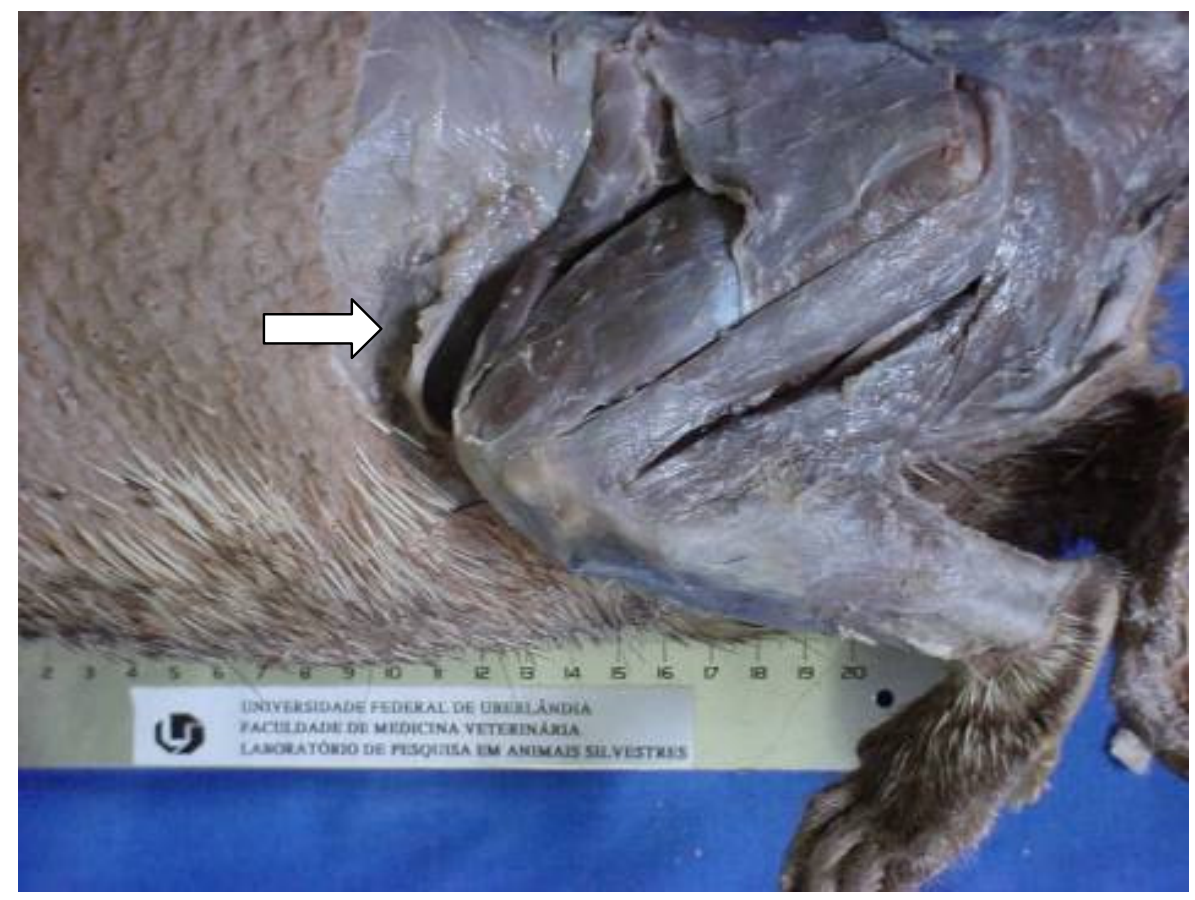

Figura 2: Fotografia do membro pélvico de Coendou prehensilis. A seta branca evidencia o tecido conjuntivo que fixa a articulação do joelho ao músculo oblíquo abdominal externo. 

femuro-tibio-patelar de Coendou prehensilis (LINNAEUS, 1758) (Rodentia, Erethizontidae). PUBVET, Londrina, V. 5, N. 18, Ed. 165, Art. 1116, 2011.

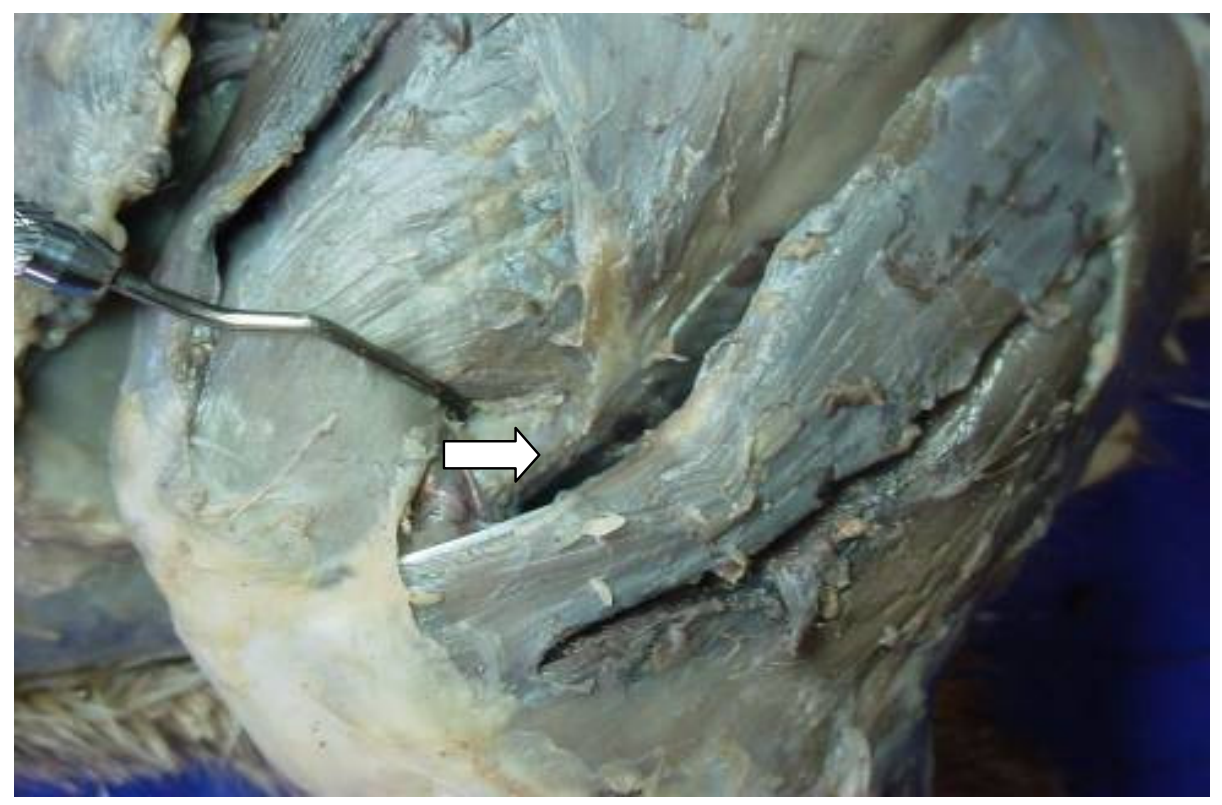

Figura 3: Fotografia da abordagem do terço médio do fêmur (seta branca) de Coendou prehensilis, obtida após o afastamento cranial do músculo vasto lateral e afastamento caudal da parte cranial do bíceps femoral.

\section{CONCLUSÃO}

É possível acessar as porções média e distal do fêmur e articulação femurotibio-patelar de Coendou prehensilis através de uma técnica de abordagem simples e pouco traumática.

\section{REFERÊNCIAS}

BILGILI, H., ASLANBEY, D. Epiphyseal regional fractures of long bones. Part IV. Comparative treatment methods for distal epiphyseal regional fractures in dogs and cats. Veteriner Cerrahi Dergisi, v. 6, n. 3-4, p. 12-21, 2000.

CEMIG. Guia Ilustrado de Animais do Cerrado de Minas Gerais. 2. ed. Belo Horizonte: Editare, 2004.

GILMORE, D. R. Internal fixation of femoral fractures. In: Bojrab, M.J., Current techniques in smal animal surgery, $3^{\text {rd }}$ ed., Lea e Febiger, Philadelphia, p. 682-694, 1990.

IAMAGUTI, P.; TEIXEIRA, R. B.; PADOVANI, C. F. Ruptura do ligamento cruzado em cães. Estudo retrospectivo da reconstrução com fáscia lata. Ciência Rural, v. 28, n. 4, p. 609-615, 1998. 
MOREIRA, F. G. A.; SILVA, S. S.; CUNHA, H. F. Impacto no Atropelamento de Animais Silvestres na Rodovia GO 060, Trecho Goiânia - Iporá. IV Seminário de Iniciação Científica. $\quad$ Disponível

http://www.prp.ueg.br/06v1/conteudo/pesquisa/iniccien/eventos/sic2006/arquivos/biologicas/1 mpacto atropelamento.pdf Acesso em 07/02/2011.

PAATSAMA, S. Ligament injuries in the canine stifle joint - a clinical and experimental study. Thesis - Royal veterinary College, Stockholm, 1952.

RAISER, A. G.; SILVEIRA, I. S.; KOMMERS,G. Osteosíntese de fratura metafisiária femural de cães com pinos de Steinmann introduzidos pela crista troclear. Revista Brasileira de Ciência veterinária, v. 5, n. 3, 123-126, 1998.

ROUSH, K. J.; Fracture manegement decisions. Veterinary Clinics of North America: Small Animal Practice, v. 25., n. 5, p. 1059-1072, 1995.

VIALLE, E; VIALLE, L. R.; BOECHAT, R.; BLEY, J. P; SCUSSIATO.; BUSATO, T.; CARVALHO, D.; FEDATTO, F.; FERNANDES, B.; TORRES, R. Produção de fratura padronizada de fêmur em ratos. Revista Brasileira de Ortopedia, v. 39, n.6, p.323-329, 2004. 